\title{
Hsa-miR-1246, hsa-miR-320a and hsa-miR-196b-5p inhibitors can reduce the cytotoxicity of Ebola virus glycoprotein in vitro
}

\author{
SHENG MiaoMiao $^{1 \dagger}$, ZHONG Ying $^{1 \dagger}$, CHEN Yang ${ }^{2}$, DU JianChao ${ }^{1}, \mathrm{JU}_{\mathrm{X}}$ XiangWu ${ }^{1}$, \\ ZHAO Chen ${ }^{1}$, ZHANG GuiGen ${ }^{1}$, ZHANG LiFang ${ }^{1}$, LIU KangTai ${ }^{1}$, YANG Ning ${ }^{1}$, \\ XIE Peng ${ }^{2}$, LI DangSheng ${ }^{3}$, ZHANG Michael Q. ${ }^{2,4 *} \&$ JIANG Cheng Yu ${ }^{1,5^{*}}$ \\ ${ }^{1}$ State Key Laboratory of Medical Molecular Biology, Institute of Basic Medical Sciences, Chinese Academy of Medical Sciences; Department \\ of Biochemistry and Molecular Biology, Peking Union Medical College, Tsinghua University; Beijing 100005, China; \\ ${ }^{2}$ MOE Key Laboratory of Bioinformatics and Bioinformatics Division, Center for Synthetic and System Biology, TNLIST/Department of \\ Automation, Tsinghua University, Beijing 100084, China \\ ${ }^{3}$ Shanghai Institutes for Biological Sciences, Chinese Academy of Sciences, Shanghai 200031, China; \\ ${ }^{4}$ Department of Molecular and Cell Biology, Center for Systems Biology, The University of Texas, Dallas 800 West Campbell Road, RL11 \\ Richardson, TX 75080-3021, USA \\ ${ }^{5}$ State Key Laboratory of Biotherapy/Collaborative Innovation Center for Biotherapy, West China Hospital, Sichuan University, Chengdu \\ 610000, China
}

Received August 16, 2014; accepted August 20, 2014; published online September 12, 2014

\begin{abstract}
Ebola virus (EBOV) causes a highly lethal hemorrhagic fever syndrome in humans and has been associated with mortality rates of up to $91 \%$ in Zaire, the most lethal strain. Though the viral envelope glycoprotein (GP) mediates widespread inflammation and cellular damage, these changes have mainly focused on alterations at the protein level, the role of microRNAs (miRNAs) in the molecular pathogenesis underlying this lethal disease is not fully understood. Here, we report that the miRNAs hsa-miR-1246, hsa-miR-320a and hsa-miR-196b-5p were induced in human umbilical vein endothelial cells (HUVECs) following expression of EBOV GP. Among the proteins encoded by predicted targets of these miRNAs, the adhesion-related molecules tissue factor pathway inhibitor (TFPI), dystroglycan1 (DAG1) and the caspase 8 and FADD-like apoptosis regulator (CFLAR) were significantly downregulated in EBOV GP-expressing HUVECs. Moreover, inhibition of hsa-miR-1246, hsa-miR-320a and hsa-miR-196b-5p, or overexpression of TFPI, DAG1 and CFLAR rescued the cell viability that was induced by EBOV GP. Our results provide a novel molecular basis for EBOV pathogenesis and may contribute to the development of strategies to protect against future EBOV pandemics.
\end{abstract}

Ebola virus, glycoprotein, microRNAs, cytotoxicity

Citation: Sheng MM, Zhong Y, Chen Y, Du JC, Ju XW, Zhao C, Zhang GG, Zhang LF, Liu KT, Yang N, Xie P, Li DS, Zhang MQ, Jiang CY. Hsa-miR-1246, hsa-miR-320a and hsa-miR-196b-5p inhibitors can reduce the cytotoxicity of Ebola virus glycoprotein in vitro. Sci China Life Sci, 2014, 57: 959-972, doi: 10.1007/s11427-014-4742-y

Ebola virus (EBOV) is an aggressive, virulent pathogen that causes a highly lethal hemorrhagic fever syndrome in humans and non-human primates [1]. To date, five species of Ebola virus have been identified: Zaire EBOV, Sudan

$\dagger$ Contributed equally to this work

*Corresponding author (email: jiang@ pumc.edu.cn; michael.zhang@utdallas.edu)
EBOV, Ivory Coast EBOV, Reston EBOV and Bundibugyo EBOV [2]. Of these, Zaire EBOV is the most deadly pathogenic strain, with mortality rates of up to $91 \%$ [3]. Previous studies have demonstrated that the viral glycoprotein (GP) plays a crucial role in the manifestations of EBOV infection, including inflammatory dysregulation, immune suppression 
and a loss of vascular integrity [4,5].

EBOV GP is a highly glycosylated transmembrane protein that forms spikes on the virion, where it mediates receptor [6-14] binding on the host cell and subsequent fusion of the viral and host membranes $[15,16]$. GP consists of a single $160 \mathrm{kD}$ precursor, which is cleaved into two disulfide-linked subunits, GP1 and GP2 [17]. Expression of EBOV GP from recombinant adenoviruses or transfected plasmids induces cell detachment and injury in several cell lines, including human umbilical vein endothelial cells (HUVECs) [4]. The cytotoxicity of EBOV GP on vein endothelial cells is believed to contribute to the disruption of blood vessel integrity and to increase vascular permeability; these processes may be some of the most important events during EBOV infection and are likely to be a major cause of death in patients with Ebola hemorrhagic fever $[18,19]$. Similar to live Ebola virus infections, overexpression of GP leads to the detachment of infected vein endothelial cells and cytotoxicity [20,21], suggesting that GP overexpression in the HUVECs model could be used to investigate the mechanisms involved in EBOV GP-mediated cytotoxicity.

Previous studies have shown important roles of cell surface molecules, such as integrins and epidermal growth factor receptor, and immune signaling molecules including MHC class I upon GP infection [4]. In addition, dynamin-dependent protein-trafficking pathway [22] and ERK signaling cascade [23] were also involved in GP-mediated cytotoxicity. Moreover, GP has other functions including induction of anoikis [19], stimulation of cytokines [24] and tissue factors [25,26] secreted from monocytes/macrophages and dendritic cells which induced the endothelial disturbances and coagulation irregularities [18,27,28]. Although GP expression induces changes in cell surface protein levels, the molecular mechanisms and cellular signaling events underlying EBOV pathogenesis remain to be further elucidated.

microRNAs (miRNAs) are endogenous small noncoding RNAs of length 18-23 nucleotides (nt) that play a significant role in various physiological processes, including cell growth, differentiation, metabolism and apoptosis [29,30]. Recent studies have shown that miRNAs were critical modulators in host-virus interaction and were thought to play a major role in viral pathogenesis [31]. miR-32 restricted the accumulation of the retrovirus primate foamy virus type 1 (PFV-1) in human cells [32]. Hsa-miR-146a maintained Epstein-Barr virus (EBV) latency by modulating innate immune responses [33]. miR-323, miR-491, and miR-654 impeded replication of the $\mathrm{H} 1 \mathrm{~N} 1$ influenza $\mathrm{A}$ virus by binding to the PB1 gene [34]. Thus, further studies of miRNAs mediated cross-talk in viral infections would help us not only to understand the basic biological processes induced by virus, but also to develop novel biomarkers and therapeutics.

Here, we report that the expression of the miRNAs hsa-miR-1246, hsa-miR320a and hsa-miR-196b-5p in
HUVECs increased upon infection with EBOV GPexpressing adenovirus. Up-regulation of these miRNAs led to decreased protein expression levels of tissue factor pathway inhibitor (TFPI), dystroglycan1 (DAG1) and Caspase 8 and FADD-like apoptosis regulator (CFLAR). Inhibitors of hsa-miR-1246, hsa-miR-320a and hsa-miR-196b-5p could effectively ameliorate cytotoxicity induced by EBOV GP, and may therefore represent potential therapeutics for treating Ebola virus infections.

\section{Materials and methods}

\subsection{Cell lines and primary cell types}

Human embryonic kidney 293T cells and 293A cells were purchased from the Peking Union Medical College Cell Culture Center and cultured in Dulbecco's modified Eagle's medium (DMEM; Gibco, Life Technologies, USA) supplemented with $10 \%$ fetal bovine serum (FBS), penicillin $\left(100 \mathrm{U} \mathrm{mL}^{-1}\right)$ and streptomycin $\left(100 \mathrm{mg} \mathrm{mL}^{-1}\right)$ at $37^{\circ} \mathrm{C}$ with $5 \% \mathrm{CO}_{2}$. Human umbilical vein endothelial cells (HUVECs; Sciencell, USA) were maintained in endothelial cell medium (ECM; Sciencell) with 5\% FBS (Sciencell, Cat. No. 0025), $1 \%$ endothelial cell growth supplement (ECGS; Sciencell, Cat. No. 1052) and 1\% penicillin/streptomycin solution (Sciencell, P/S, Cat. No. 0503).

\subsection{High-throughput sequencing data analysis}

RNA-Seq libraries were sequenced with PE100 using Illumina HiSeq2500. To analyze the differentially expressed genes (DEGs), we performed TopHat to map the reads to human genome (HG19) and Cufflinks to get the reads per kilobases per million reads (RPKM) of each transcript [35]. Then, transcripts with more than or equal to one RPKM were defined as expressed. When the glycoprotein group and vehicle group were compared, an RNA with a fold change greater than or equal to two was defined as up-regulated; an RNA with a fold change less than or equal to 0.5 was defined as down-regulated genes.

miRNA-Seq libraries were sequenced with SE36 using an Illumina HiSeq2500. To analyze the differentially expressed miRNAs (DEmiRs), we performed miRDeep to obtain the RPM of each transcript [36]. Then, miRNAs with greater than or equal to one RPM were defined as expressed. When the glycoprotein group and the vehicle group were compared, a miRNA with a fold change greater than or equal to two was defined as up-regulated; a miRNA with a fold change less than or equal to 0.5 was defined as down-regulated.

\subsection{DEmiRs analysis and miRNA target prediction}

We performed Heatmap2, from R package gplots, to cluster DEmiRs (Supplementary Figure S1). To investigate the 
target genes of miRNAs, miRDB was used for prediction. Target genes that were down-regulated in at least one time point from 3 to $24 \mathrm{~h}$ were selected as candidate miRNA targets for following analysis.

\subsection{Plasmids and expression}

The ZEBOV GP sequence (NCBI, Ebola virus-Mayinga, Zaire, 1976, NP_066246) was codon-optimized to increase the protein expression in mammalian cells [37]. The sequence of GP was further optimized by removing the new splice sites and optimizing the secondary structure; it was then synthesized by Sangon Biotech (China). The optZGP sequence was inserted into pEAK13 expression vector and pAd-TrackCMV vector (Quantum Biotechnologies) [38], the pAd-TrackCMV vector is designed for simultaneous expression of purpose protein and green fluorescent protein (GFP), and then the constructs were confirmed by sequencing. EboZ GP mutant lacking the mucin-like domain at the $\mathrm{C}$ terminus of GP1 (GP- $\triangle$ mucin) was constructed by overlapping extension PCR. TFPI, DAG1, CFLAR, KIAA1429 and $\mathrm{ZCCHC6}$ sequences were amplified from human lung cDNA (Invitrogen, USA) using Q5 High-Fidelity DNA Polymerase (New England Biolabs, USA), and their coding sequences were cloned into the pEAK13 expression vector. All primer sequences for PCR are listed in Supplementary Table S1. HEK293T cells were co-transfected with $0.5 \mu \mathrm{g}$ Peak13-GP-gfp or Peak13-GP- $\Delta$ mucin and $0.5 \mu \mathrm{g}$ Peak13-TFPI-flag/Peak13-DAG1-flag/Peak13-CFLAR-flag using Lipofectamine 2000 (Invitrogen). At $48 \mathrm{~h}$ post-transfection, the cells were monitored to determine the extent of rounding; both floating and adherent cells were counted to calculate percentage of detachment.

\subsection{Production and assay of adenovirus vectors}

The production of adenovirus vectors with E1/E3 deleted was carried out as previously described [38]. The virus was titered by limiting dilution in 293A cells. An adenovirus vector expressing EboZ GP (Ad-GP) and mock vector (Ad- $\triangle \mathrm{E} 1)$ were used to transduce HUVECs (MOI, 500). The cells were monitored at regular intervals for evidence of cell rounding, and total RNA was obtained at the indicated time points with TRIZOL reagent in accordance with the manufacturer's protocol (Invitrogen).

\section{6 miRNA inhibitor and mimic}

All miRNA inhibitor and mimic were obtained from Ribo Biotechnology, China. The sequence of micrOFFTM miRNA inhibitor control was as follows: 5'-mUmCmUmAmCmUmCmUmUmUmCmUmAmGmGmAmGmGmUmUmGmUmGmA-3'; the sequence of hsa-miR-1246 was as fol- lows: 5'-mCmCmUmGmCmUmCmCmAmAmAmAmAmUmCmCmAmUmU-3'; the sequence of hsa-miR-320a was as follows: 5'-mUmCmGmCmCmCmUmCmUmCmAmAmCmCmCmAmGmCmUmUmUmU-3'; the sequence of hsa-miR-196b-5p was as follows: 5'-mCmCmCmAmAmCmAmAmCmAmGmGmAmAmAm CmUm AmCmCmUmA-3'.

\subsection{Cell viability assays}

Cell viability was determined by MTS assay (Promega, USA). HUVECs were seeded at a concentration of $1 \times 10^{5}$ $\mathrm{mL}^{-1}$ in 96-well plates and subsequently challenged with Ad-GP (MOI, 500) or an equal volume of Ad- $\Delta \mathrm{E} 1$ at the indicated time points $(0,3,6,12,24,36$, and $48 \mathrm{~h})$. The medium was then removed from each well, and the wells were washed twice with PBS. Next, $100 \mu \mathrm{L}$ of fresh medium and $20 \mu \mathrm{L}$ of Cell Proliferation Assay solution were added. The cells were incubated at $37^{\circ} \mathrm{C}$ for $1 \mathrm{~h}$ before the absorbance was measured at $490 \mathrm{~nm}$. In the miRNA inhibitor/mimic rescue assays, miRNA inhibitors/mimics (final concentration, $100 \mathrm{nmol} \mathrm{L}{ }^{-1}$ ) were transfected into HUVECs with Lipofectamine RNAiMAX (Invitrogen) $24 \mathrm{~h}$ before the cells were exposed to Ad-GP and Ad- $\Delta$ E1.

\subsection{Western blot analysis}

HUVECs $\left(1 \times 10^{5} \mathrm{~mL}^{-1}\right)$ were transfected in 6-well plates with $100 \mathrm{nmol} \mathrm{L}{ }^{-1}$ control miRNA inhibitor, hsa-miR-1246 inhibitor, hsa-miR-196b-5p inhibitor and hsa-miR-320a inhibitor using Lipofectamine RNAiMAX (Invitrogen); 24 $\mathrm{h}$ later, the cells were treated with Ad-GP and Ad- $\Delta \mathrm{E} 1$ control. After $24 \mathrm{~h}$, the cells were lysed with ice-cold RIPA and denatured for $10 \mathrm{~min}$ at $95^{\circ} \mathrm{C}$. The production of Western blot was carried out as previously described [23]. All primary antibodies for Western blot are listed in Supplementary Table S2.

\subsection{Luciferase activity assay}

Vectors used in the luciferase activity assay were made by Sangon Biotech, and wild-type and mutant-type target gene 3' UTRs were cloned into the Not I and Xho I sites of the psiCHECk-2 vectors (Promega). Both constructs were verified by sequencing. $293 \mathrm{~T}$ cells were cultured in 24-well plates, and each was transfected with $100 \mathrm{nmol} \mathrm{L}^{-1}$ control miRNA mimic, hsa-miR-1246 mimic, hsa-miR-320a mimic and hsa-miR-196b-5p mimic using Lipofectamine RNAi MAX (Invitrogen). After $24 \mathrm{~h}, 1 \mu \mathrm{g}$ of either wild-type vector or mutant vector containing Renilla luciferase as well as firefly luciferase as an internal control were transfected into 293T cells using Lipofectamine 2000 (Invitrogen). At $48 \mathrm{~h}$ post-transfection, the relative luciferase activity was calculated by normalizing the Renilla luminescence to the 
firefly luminescence using the Dual-Luciferase Reporter Assay (Promega) according to the manufacturer's instructions. Values represent the mean \pm standard error of the mean (SEM) of three experiments from three independent assays.

\subsection{0 siRNA-mediated knockdown}

The negative control siRNA and TFPI/DAG1/CFLAR/ KIAA1429/ZCCHC6/CPD-specific short interfering RNAs were obtained from Ribo Biotechnology, China. HUVECs $\left(1 \times 10^{5} \mathrm{~mL}^{-1}\right)$ were transfected with $100 \mathrm{nmol} \mathrm{L}^{-1}$ siRNA using Lipofectamine RNAiMAX transfection reagent (Invitrogen). After $24 \mathrm{~h}$ of incubation, HUVECs were transduced with an adenovirus expression vector containing EboZ GP or mock; $48 \mathrm{~h}$ later, the cells were harvested and analyzed to determine both GP cytotoxicity by MTS assay and the effect of TFPI/DAG1/CFLAR/KIAA1429/ZCCHC6/CPDspecific knockdown by Western blot analysis. The blots were analyzed with antibodies against the indicated proteins (Quantity One, Bio-Rad, USA), as described earlier. The sequence of TFPI-specific siRNA was as follows: 5' CUGGAAUAUGUCGAGGUUA dTdT 3'/3' dTdT GACCUUAUACAGCUCCAAU 5'. The sequence of DAG1specific siRNA was as follows: 5' GCACUGGUGUUGAAUGACA dTdT 3'/3' dTdT CGUGACCACAACUUACUGU 5'. The sequence of CFLAR-specific siRNA was as follows: 5' GAUGUG UCCUCAUUAAUUU dTdT 3'/3' dTdT CUACA CAGGAGUAAUUAAA 5'. The sequence of KIAA1429-specific siRNA was as follows: $5^{\prime}$ GGUUGUUACUGCU GGUUCA dTdT 3'/3' dTdT CCAACAAUGACGACCAAGU 5'. The sequence of ZCCHC6specific siRNA was as follows: 5' CAAGAGAAACGCCGAUUAA dTdT 3'/3' dTdT GUUCUCUUUGCGGCUAAUU 5'. The sequence of CPD-specific siRNA was as follows: 5' GCCAUUGACUGUUACUAAU dTdT 3'/3' dTdTCGGUAA CUGACAAUGA UUA 5'.

\subsection{Statistical analysis}

Statistical significance was determined using a two-tailed Student's $t$-test unless indicated otherwise. A value of $P<0.05$ was considered statistically significant.

\section{Results}

\subsection{Differential miRNAs expression in EBOV GP- expressing HUVECs}

EBOV GP plays a key role in the manifestations of EBOV infection, including inflammatory dysregulation, immune suppression and a loss of vascular integrity [4,6,20,22,39]. However, these changes have mainly focused on alterations at the protein level. As miRNAs have been increasingly shown to be important in various viral infections, it is quite interesting to explore the role of miRNAs in the molecular pathogenesis underlying EBOV GP-induced cytotoxicity. We infected HUVECs with GP-expressing adenovirus (Ad-GP) and Ad- $\Delta \mathrm{E} 1$, which served as a vehicle control. After $24 \mathrm{~h}$, cell rounding and detachment were observed in the Ad-GP-infected (but not in the Ad- $\Delta$ E1-infected) HUVECs cultures (Supplementary Figure S2A and B), and similar results were obtained in 293T cells (Supplementary Figure S2C and D). The percentage of detached and injured cells was analyzed using MTS assay and cell viability was decreased to approximately $50 \%$ at $48 \mathrm{~h}$ after Ad-GP treatment compared to Ad- $\Delta \mathrm{E} 1$ control treatment (Supplementary Figure S2E). Therefore, the cell rounding and death model induced by EBOV GP was established.

Then, RNA extracts were isolated from Ad-GP- and Ad- $\triangle$ E1-infected HUVECs at 0, 3, 6, 12, 24, 36, and $48 \mathrm{~h}$ after infection and were sent for next generation sequencing. Among the 13 samples of RNA-Seq data and miR-Seq data that were analyzed (Supplementary Figure S1), 18 miRNAs were found to be significantly differentially expressed by at least one time point from 3 to $24 \mathrm{~h}$ in the Ad-GP-infected cells as compared with Ad- $\Delta$ E1-infected HUVECs (Figure 1; Supplementary Table S3).

\subsection{Hsa-miR-1246, hsa-miR-320a and hsa-miR-196b-} $5 p$ were involved in EBOV GP-induced cytotoxicity

To further investigate the biological significance of these differentially expressed miRNAs, we transfected HUVECs with mimics or inhibitors of selected miRNAs $24 \mathrm{~h}$ before the cells were exposed to Ad-GP or Ad- $\Delta \mathrm{E} 1$, and cell viability and detachment were analyzed $48 \mathrm{~h}$ after infection. None of the miRNA mimics demonstrated any effect on cell viability (Figure 2B); only inhibitors of hsa-miR-1246, hsa-miR-320a and hsa-miR-196b-5p could effectively ameliorate EBOV GP-induced cytotoxicity (Figure 2A). Thus, we focused on the role of these three miRNAs. The hsa-miR-1246 inhibitor was the most effective at rescuing cell detachment, which fits with the fact that levels of this miRNA increased the most in HUVECs infected after 3 or 6 h (Figure 1; Supplementary Table S3). These results indicated that elevated levels of these three miRNAs may play a key role in EBOV GP-induced cytotoxicity.

2.3 TFPI, DAG1, CFLAR, ZCCHC6 and TRIM24 protein levels were up-regulated by hsa-miR-1246, hsa-miR-320a and hsa-miR-196b-5p inhibitors in EBOV GP-expressing HUVECs

To investigate the potential molecular mechanisms through which EBOV GP-induced hsa-miR-1246, hsa-miR-320a and hsa-miR-196b-5p mediate cytotoxicity, we analyzed the target genes of these miRNAs using the miRDB database. We found that hsa-miR-1246, hsa-miR-320a and hsa-miR196b-5p had eight, nine, and five potential target genes, respectively, making a total of 21 potential target genes 
(Table 1).

Western blot analysis showed that seven of 21 candidate target genes were down-regulated in Ad-GP group as com- pared with Ad- $\Delta \mathrm{E} 1$ group, and inhibition of any one of these three miRNAs could significantly enhance the expression of five proteins: TFPI, DAG1, CFLAR, zinc finger

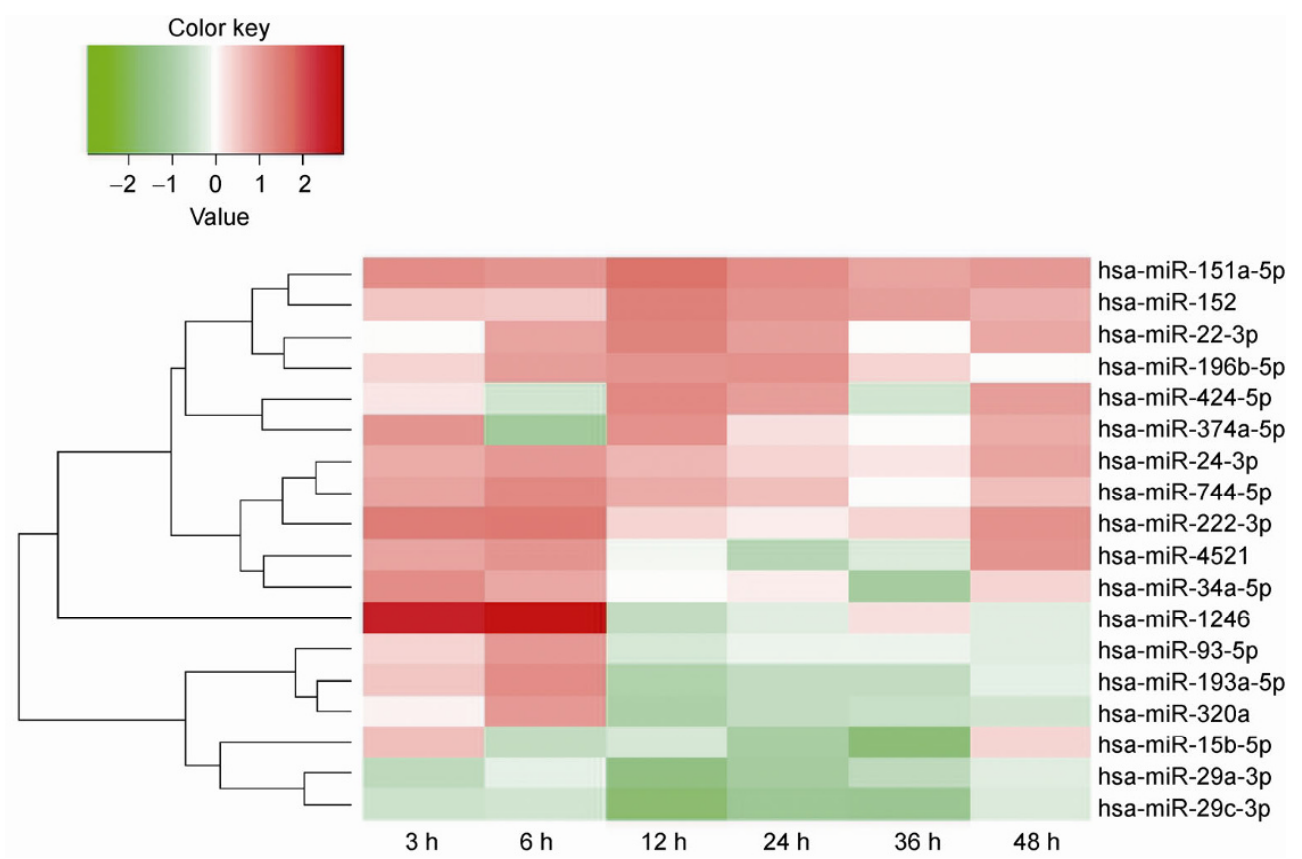

Figure 1 Eighteen miRNAs were involved in GP induced cytotoxicity. Heat map shows time-course fold changes of selected 18 significant DEmiRs in glycoprotein-induced vascular endothelial cell injury. A red block indicates up-regulated genes and a green block indicates down-regulated genes. Each expression result is labeled with the official symbol of the miRNA from miRBase.

Table 1 The differentially expressed target genes of three miRNAs

\begin{tabular}{|c|c|c|c|c|c|c|c|}
\hline miRNAs & Gene ID & Gene & Ad- $\Delta \mathrm{E} 1$ & Ad-GP & Fold change & $\log 2$ & Abs \\
\hline \multicolumn{8}{|c|}{ Hsa-miR1246 } \\
\hline & 79772 & MCTP1 & 62.8404 & 31.0496 & 0.4941 & -1.0171 & 1.0171 \\
\hline & 7328 & UBE2H & 6.24955 & 3.06634 & 0.4906 & -1.0272 & 1.0272 \\
\hline & 79670 & ZCCHC6 & 3.84888 & 1.87644 & 0.4875 & -1.0364 & 1.0364 \\
\hline & 6498 & SKIL & 7.65524 & 3.66433 & 0.4787 & -1.0629 & 1.0629 \\
\hline & 8837 & CFLAR & 9.39462 & 4.34707 & 0.4627 & -1.1118 & 1.1118 \\
\hline & 122786 & FRMD6 & 9.74299 & 4.35498 & 0.4470 & -1.1617 & 1.1617 \\
\hline & 84268 & RPAIN & 10.5843 & 4.24862 & 0.4014 & -1.3169 & 1.3169 \\
\hline \multicolumn{8}{|c|}{ Hsa-miR196b-5p } \\
\hline & 10479 & SLC9A6 & 3.0474 & 1.4090 & 0.4624 & -1.1129 & 1.1129 \\
\hline & 6386 & SDCBP & 3.3731 & 1.4383 & 0.4264 & -1.2297 & 1.2297 \\
\hline & 3964 & LGALS8 & 4.1873 & 1.7810 & 0.4253 & -1.2333 & 1.2333 \\
\hline & 3910 & LAMA4 & 31.8476 & 11.6351 & 0.3653 & -1.4527 & 1.4527 \\
\hline \multicolumn{8}{|c|}{ Hsa-miR320a } \\
\hline & 6596 & HLTF & 7.7760 & 3.7750 & 0.4855 & -1.0425 & 1.0425 \\
\hline & 7035 & TFPI & 364.7290 & 175.4280 & 0.4810 & -1.0559 & 1.0559 \\
\hline & 3269 & HRH1 & 3.9470 & 1.8268 & 0.4628 & -1.1115 & 1.1115 \\
\hline & 1362 & CPD & 12.3998 & 5.6404 & 0.4549 & -1.1364 & 1.1364 \\
\hline & 11082 & ESM1 & 9.4389 & 4.2075 & 0.4458 & -1.1656 & 1.1656 \\
\hline & 9589 & WTAP & 9.8388 & 3.8808 & 0.3944 & -1.3422 & 1.3422 \\
\hline & 8805 & TRIM24 & 7.3172 & 2.8571 & 0.3905 & -1.3568 & 1.3568 \\
\hline & 25962 & KIAA1429 & 4.4740 & 1.4920 & 0.3335 & -1.5843 & 1.5843 \\
\hline & 1605 & DAG1 & 5.9065 & 1.5626 & 0.2646 & -1.9183 & 1.9183 \\
\hline
\end{tabular}


CCHC domain-containing 6 (ZCCHC6) and tripartite motif containing 24 (TRIM24). Additionally, inhibition of hsamiR-320a or hsa-miR-196b-5p enhanced the expression of carboxypeptidase D (CPD) and KIAA1429 (Figure 3; Supplementary Figure S3).

To our surprise, although the inhibitory effects of hsamiR-1246 on TFPI, DAG1 and TRIM24 were identified by Western blot analysis, the predicted hsa-miR-1246 target gene list did not include TFPI, DAG1 and TRIM24. Similarly, CFLAR and ZCCHC6 were not included in the predicted hsa-miR-320a target gene list, and TFPI, DAGl, CFLAR, ZCCHC6, CPD and TRIM24 were not included in the predicted hsa-miR-196b-5p target gene list (Table 1), indicating that further optimization of the miRDB database is necessary. Nevertheless, these findings suggest that these genes might be regulated by hsa-miR-1246, hsa-miR-320a, and hsa-miR-196b-5p in EBOV-induced cytotoxicity of HUVECs.

To determine whether TFPI, DAG1, CFLAR, ZCCHC6, $C P D$, TRIM24 and KIAA1429 are direct targets of hsamiR-1246, hsa-miR-320a and hsa-miR-196b-5p, we constructed recombinant plasmids that contained a luciferase gene that had been fused with the native or mutated $3^{\prime}$ UTR mRNA sequences of the potential target genes. Analysis of luciferase activity in the presence of hsa-miR-1246, hsa-miR-320a and hsa-miR-196b-5p indicated that CFLAR and ZCCHC6 may be direct targets of hsa-miR-1246; TFPI, $D A G 1, C P D$ and KIAA1429 may be direct targets of hsa-miR-320a; and TFPI may be the only direct target of hsa-miR-196b-5p (Figure 4; Supplementary Figure S4).

\subsection{Forced expression of TFPI, DAG1 and CFLAR ameliorated EBOV GP-induced cytotoxicity}

To further investigate the roles of the identified target genes (TFPI, DAG1, CFLAR, KIAA1429, ZCCHC6 and CPD) in EBOV GP-induced cytotoxicity, we knocked down their protein expression in HUVECs before infection with Ad-GP (Figure 5A-F; Supplementary Figure S5A-F). Cell death induced by EBOV GP became more severe when the protein expressions of TFPI, DAG1 and CFLAR were downregulated (Figure 5A-F). In contrast, the cell detachments induced by EBOV GP in transfected HEK293T cells were significantly reduced when the TFPI, DAG1 and CFLAR

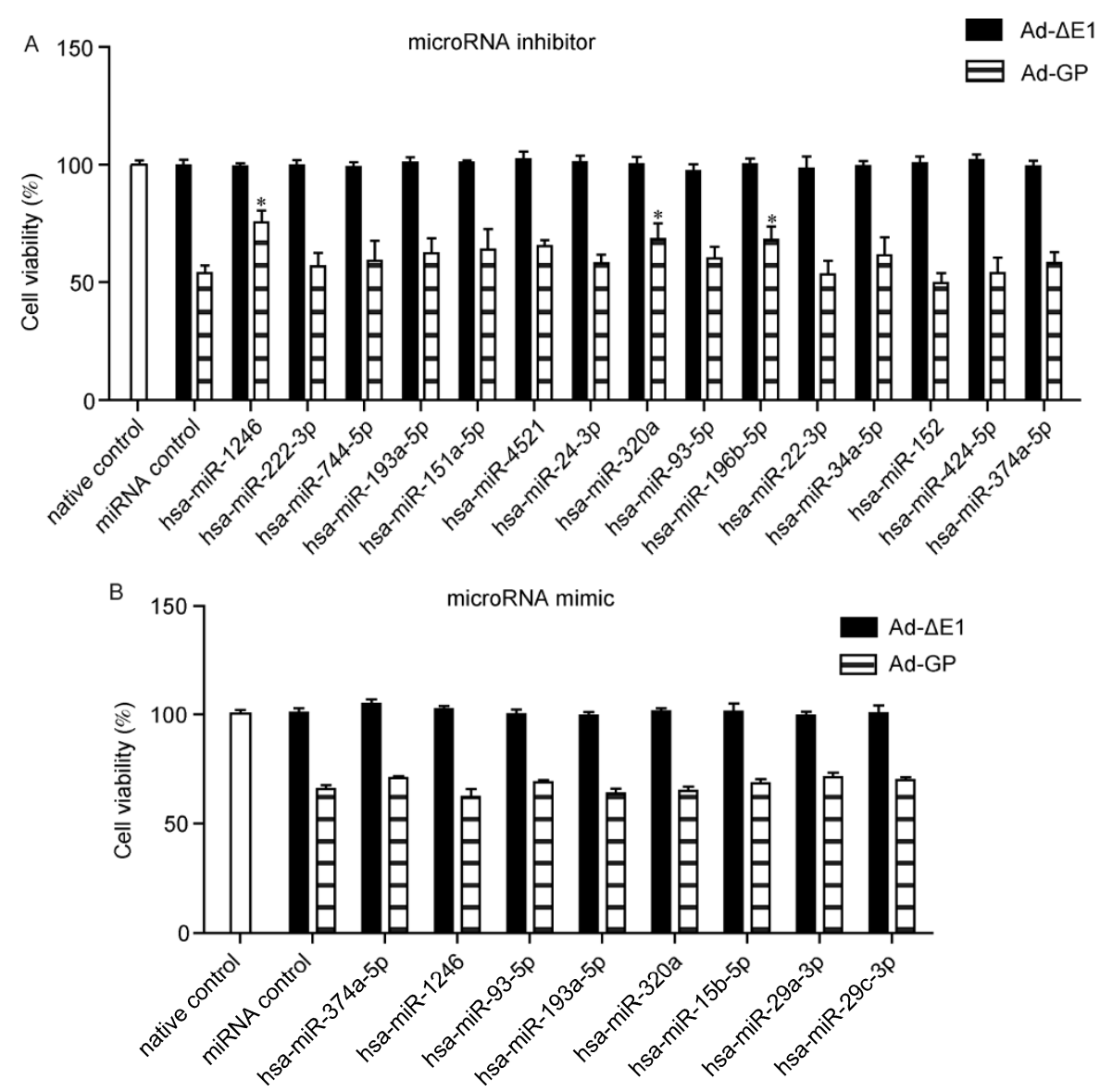

Figure 2 Inhibitors of hsa-miR-1246, hsa-miR-196b-5p and hsa-miR-320a could ameliorate cell death induced by EBOV GP. HUVECs were transfected with control inhibitors or miRNA inhibitors (A) (control mimics or miRNA mimics, B) as indicated at a final concentration of $100 \mathrm{nmol} \mathrm{L}^{-1}$. After $24 \mathrm{~h}$, the cells were exposed to Ad-GP and Ad- $\Delta \mathrm{E} 1$ (MOI, 500). After $48 \mathrm{~h}$, the cell viability was assayed. The data are shown as the mean $\pm \mathrm{SEM}$ of three independent experiments. *, $P<0.05$. 

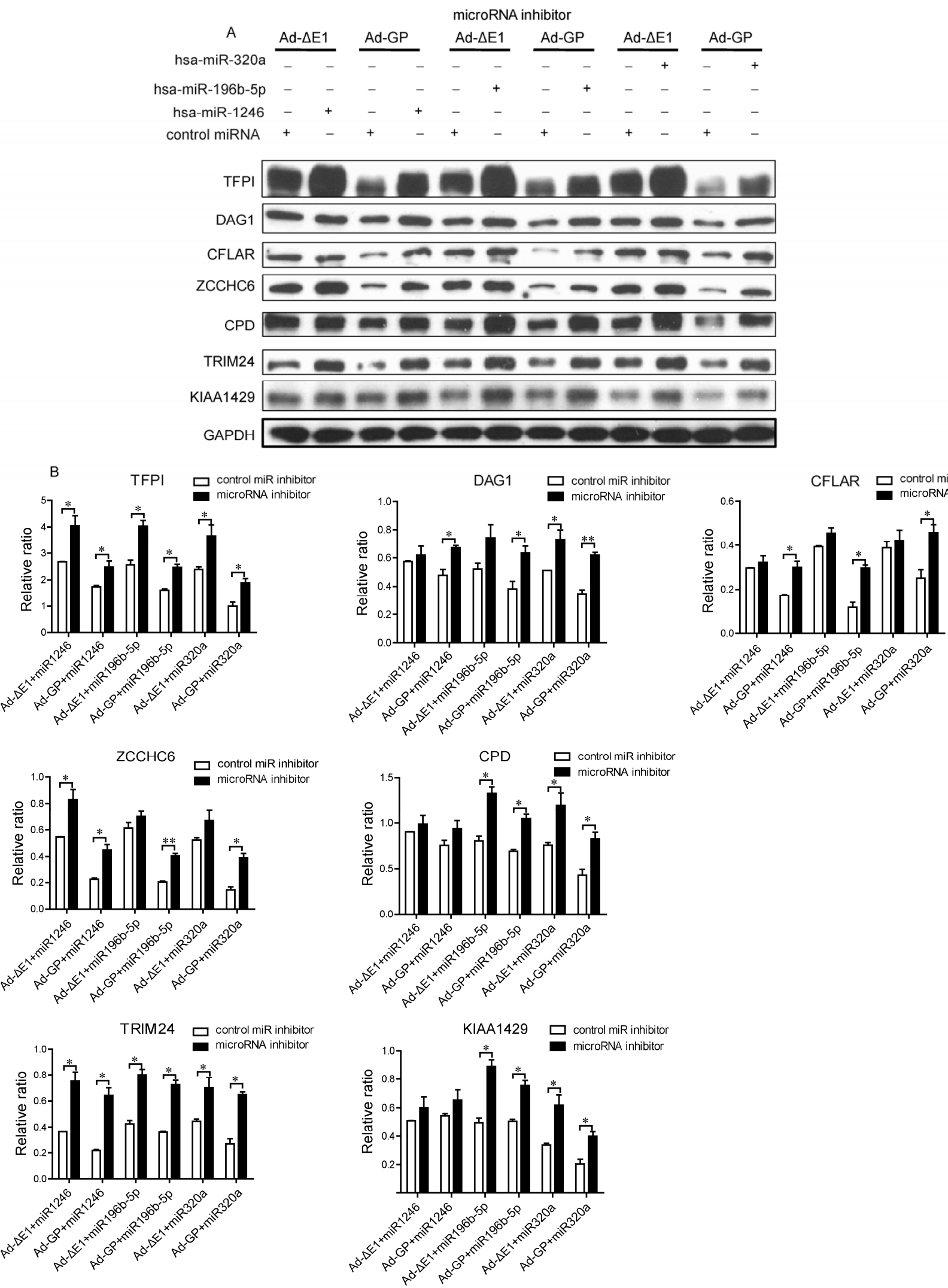

Figure 3 Identification of direct target genes of hsa-miR-1246, hsa-miR-196b-5p and hsa-miR-320a by Western blot in HUVECs. A, Hsa-miR1246, hsa-miR320a and hsa-miR196b-5p inhibitors (final concentration, $100 \mathrm{nmol} \mathrm{L}^{-1}$ ) were transfected into HUVECs $24 \mathrm{~h}$ before the cells were exposed to Ad-GP and Ad- $\Delta$ E1 (MOI, 500). Target gene expression was analyzed at $24 \mathrm{~h}$ post-transduction by Western blot. The blots were analyzed with antibodies against the indicated proteins. B, The bar graph shows the DAG1/GAPDH, TFPI/GAPDH, CFLAR/GAPDH, ZCCHC6/GAPDH, CPD/GAPDH, TRIM24/GAPDH and KIAA1429/GAPDH relative ratios from three experiments. *, $P<0.05$; **, $P<0.01$. 

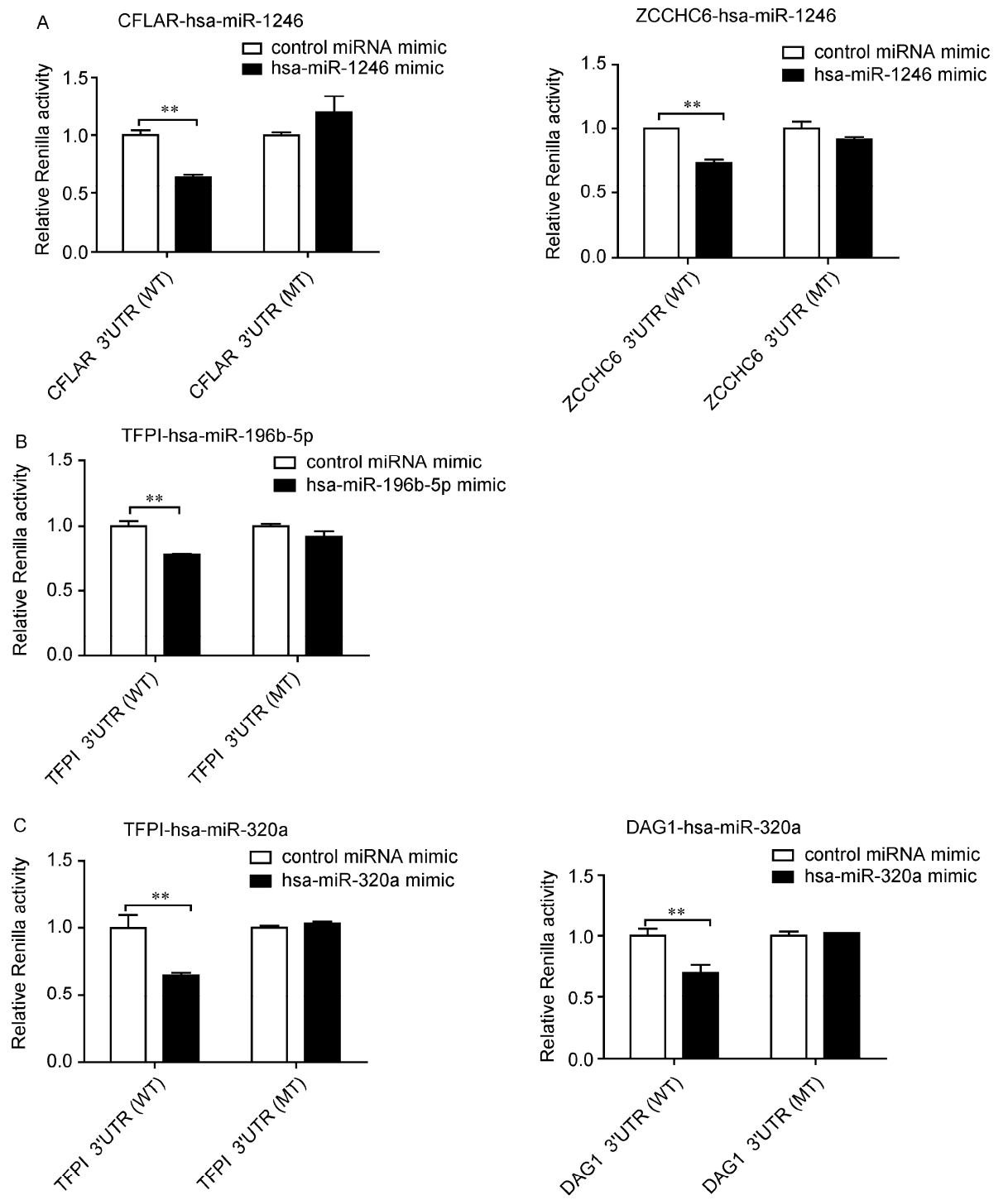

CPD-hsa-miR-320a
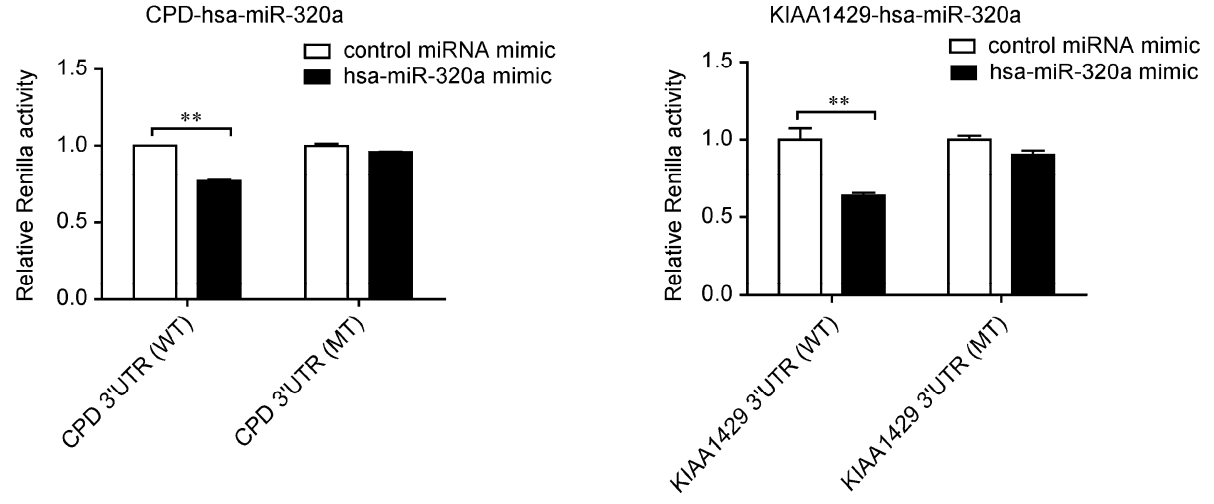

Figure 4 Identification of direct target genes of hsa-miR-1246, hsa-miR-196b-5p and hsa-miR-320a by luciferase in HEK293T cells. A, Relative luciferase activity assays of Renilla luciferase reporters with CFLAR and ZCCHC6 wild-type or mutant 3' UTRs were performed in HEK293T cells after transfection with control mimic or hsa-miR-1246 mimic. Luciferase activity was determined $48 \mathrm{~h}$ after transfection and normalized to firefly luciferase activity. Values represent the mean \pm SEM of three experiments from three independent assays. $* *, P<0.01$. B, Relative luciferase activity assays of Renilla luciferase reporters with TFPI wild-type or mutant 3' UTRs were performed in HEK293T cells after transfection with control mimic or hsa-miR-196b-5p mimic. Luciferase activity was determined $48 \mathrm{~h}$ after transfection and normalized to firefly luciferase activity. The values represent the mean \pm SEM of three experiments from three independent assays. **, $P<0.01$. C, Relative luciferase activity assays of Renilla luciferase reporters with TFPI, DAG1, CPD and KIAA1429 wild-type or mutant $3^{\prime}$ UTRs were performed in HEK293T cells after transfection with control mimic or hsa-miR-320a mimic. Luciferase activity was determined $48 \mathrm{~h}$ after transfection and normalized to the firefly luciferase activity. Values represent the mean \pm SEM of three experiments from three independent assays. **, $P<0.01$. 

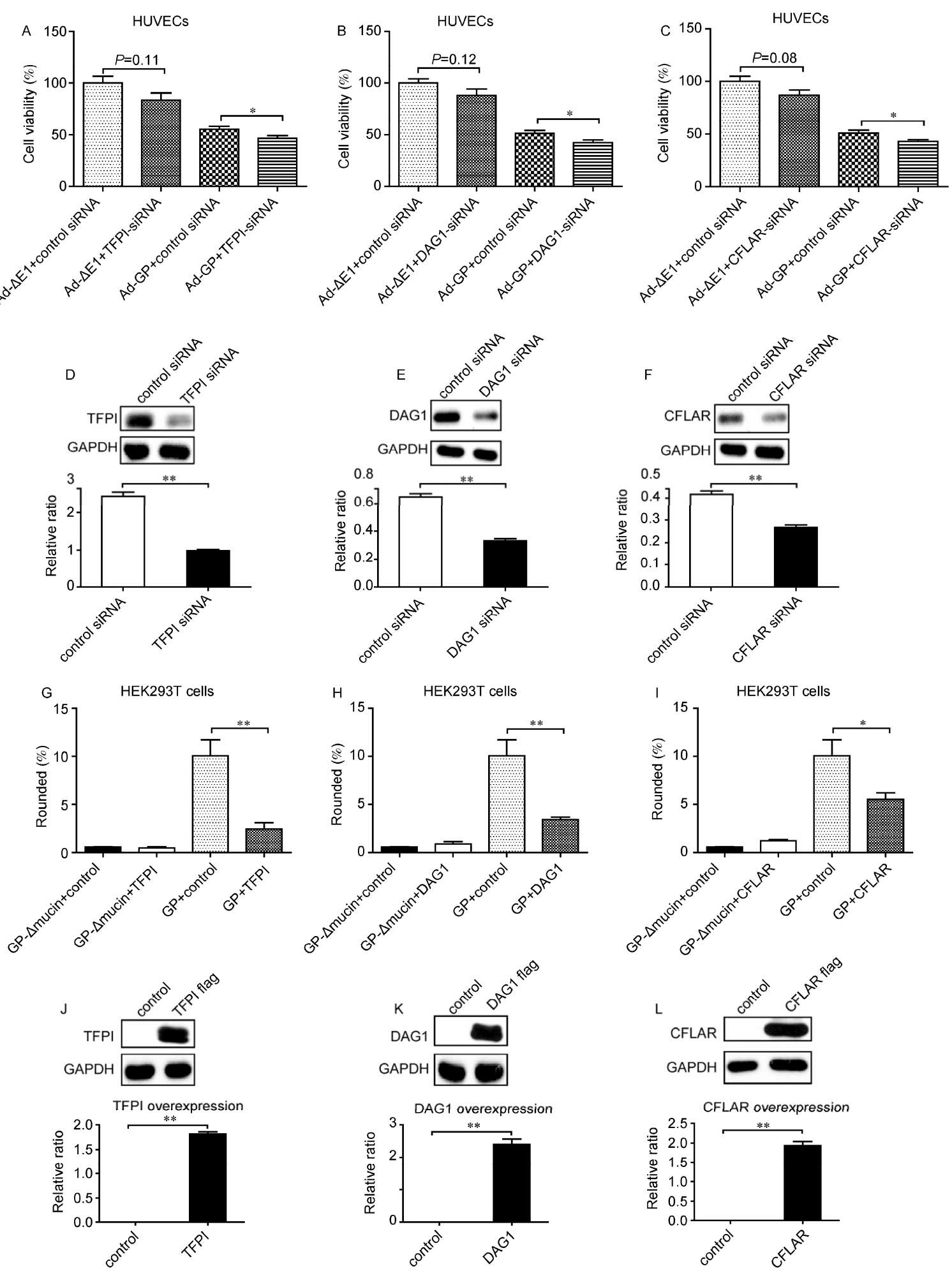

Figure 5 Forced expression of TFPI, DAG1 and CFLAR ameliorated EBOV GP-induced cytotoxicity. Control siRNA or TFPI-specific siRNA (A)/DAG1-specific siRNA (B)/CFLAR-specific siRNA (C) were transfected into HUVECs $24 \mathrm{~h}$ before the cells were exposed to Ad-GP and Ad- $\triangle$ E1 (MOI, 500), cell viability was assayed by MTS at $48 \mathrm{~h}$ after transduction. The data are from three experiments. $*, P<0.05$. Western blotting analysis of the efficiency of TFPI (D), DAG1 (E) or CFLAR (F) knockdown in HUVECs. The bar graph indicates TFPI/GAPDH, DAG1/GAPDH and CFLAR/GAPDH relative ratios. The data are shown as the mean \pm SEM of three experiments. **, $P<0.01$. HEK293T cells were cotransfected with $0.5 \mu \mathrm{g}$ of EboZ GP or EboZ GP- $\Delta$ mucin and $0.5 \mu \mathrm{g}$ of control plasmid Peak13-TFPI-flag (G), Peak13-DAG1-flag (H), Peak13-CFLAR-flag (I). The cells were incubated for $48 \mathrm{~h}$, and both floating and adherent cells were counted to calculate the percentage rounding. The data are from three experiments. *, $P<0.05 ; * *, P<0.01$. Western blotting analysis of the efficiency of TFPI (J), DAG1 (K) or CFLAR (L) overexpression in HEK293T cells. The bar graph indicates TFPI/GAPDH, DAG1/GAPDH and CFLAR/GAPDH relative ratios. The data are shown as the mean \pm SEM of three experiments. **, $P<0.01$. 
proteins were overexpressed (Figure 5G-L; Supplementary Figure S5G-J). Due to the unsatisfactory transfection efficiency of HUVECs, we chose another commonly used cells, HEK293T cells. These results indicated that TFPI, DAG1 and CFLAR may play critical roles in EBOV GP-induced cell cytotoxicity.

TFPI, DAG1 and CFLAR have been previously shown to be associated with cell adhesion [40-43], while TFPI also plays a part in the inhibition of coagulation [44] and CFLAR has an inhibitory role in apoptosis [45]. Therefore, we sought to evaluate whether the rescue effect of cell viability could be enhanced when cells were treated with these proteins in combination. We overexpressed TFPI, DAG1 and CFLAR in HEK293T cells that had been previously transfected with EBOV GP either alone or in combination (Figure 6A and B). Notably, TFPI demonstrated the most pronounced effect among the single-overexpressed proteins, and combined overexpression of all three proteins demonstrated a significantly stronger effect compared to overexpression of single proteins only (Figure 6A). Thus, these data suggested that combined therapy with TFPI, DAG1, and CFLAR may have the best rescue effect on EBOV GP-induced cytotoxicity.

\section{5 miRNA inhibitors reversed EBOV GP-induced cytotoxicity}

We next treated Ad-GP-infected HUVECs with a combination of inhibitors of hsa-miR-1246, hsa-miR-320a, and hsa-miR-196b-5p. Interestingly, the combination of all three miRNA inhibitors had a greater effect on cell viability than hsa-miR-320a or hsa-miR-196b-5p inhibitor alone, although the effect of the combined inhibitors was not significantly different compared to that of the hsa-miR-1246 inhibitor alone (Figure 6C). Furthermore, we found that only inhibitors of hsa-miR-1246 and hsa-miR-320a demonstrated a therapeutic effect on EBOV GP-induced cell rounding and detachment, although all of them demonstrated prophylactic effects (Figure 6D).

We have identified the adhesion-related molecules TFPI, $D A G 1$ and CFLAR as important target genes in EBOV GP-induced vein endothelial cell detachment, and showed that overexpression of these genes could rescue EBOV GP-mediated cytotoxicity. We also showed that hsa-miR1246, hsa-miR-320a, and hsa-miR-196b-5p were elevated following EBOV GP transfection, and inhibitors of these miRNAs could rescue EBOV GP-mediated cytotoxicity (Figure 6E).

\section{Discussion}

Cytotoxicity caused by EBOV GP is believed to play an important role in the hemorrhagic manifestations that are widely observed in patients and laboratory-infected mon- keys [4,18,20,22]. However, the molecular events that lead to these cytopathic effects during viral infection are poorly understood. Using next-generation sequencing technology and differential miRNAs expression analysis, we identified novel molecular targets that were involved in EBOV GP-induced cytotoxicity in HUVECs. Moreover, we could significantly reduce EBOV GP-induced HUVECs' death using hsa-miR-1246, hsa-miR-320a and hsa-miR-196b-5p inhibitors, both alone and in combination. We found that the sponges of hsa-miR-1246, hsa-miR-320a, and hsa-miR196b-5p were located at different genomic locations [46] (Supplementary Figure S6), and further studies of the modulation of expression of these miRNAs upon EBOV GP induction are necessary.

Previous study showed that endothelial adherens contribute to the functional integrity of the endothelium, and the mainly adherens-type junctions were the targets for increased cellular permeability after EBOV infection [24]. The adherent molecules such as transmembrane vascular endothelial cadherin, beta- and gama-catenins, integrins and EGFR were involved in the process [4,6,24]. Among the miRNA target genes identified, the protein products of TFPI, DAG1, CFLAR, ZCCHC6, CPD, TRIM24 and KIAA1429 were shown by Western blot analysis to be regulated by hsa-miR-1246, hsa-miR-320a, and hsa-miR-196b-5p (Figure 3). However, our data showed that only adhesion-related molecules (TFPI, DAGI and CFLAR) had functional roles in EBOV GP-induced cytotoxicity in HUVECs (Figure 5; Supplementary Figure S5), suggesting that adhesion indeed plays an important role in maintaining blood vessel integrity and limiting vascular permeability upon Ebola virus infection in humans. At the same time, the interaction between the three target proteins and other proteins previously implicated in GP toxicity remains to be studied.

In this study, expression of miRNAs mimic in Ad- $\triangle$ E1-infected HUVECs did not mimic the detachment effects of GP expression, which might be because overexpression of these miRNAs alone is not sufficient to induce cell detachment and death. Studies showed that pathological changes of cell morphology happened when GP protein was highly expressed but not moderately expressed [47]. It also implied that there might be other molecules involved in GP-induced cytotoxicity in addition to the target genes of hsa-miR-1246, hsa-miR-320a and hsa-miR-196b-5p.

ZCCHC6 (http://www.ncbi.nlm.nih.gov/gene/79670) and TRIM24 are transcriptional regulators [48]. They might be indirectly regulated by the miRNAs and further analysis and experiments are necessary to determine the roles of their transcriptional targets in EBOV GP-induced cytotoxicity.

It is interesting to note that TFPI showed the best rescue effect upon GP overexpression and the inhibition of hsa-miR-1246 demonstrated the best effect for miRNAs. However, TFPI is not directly targeted by hsa-miR-1246. It is likely that hsa-miR-1246 has multi-targets besides CFLAR. Further bioinformatics analysis and experimental 


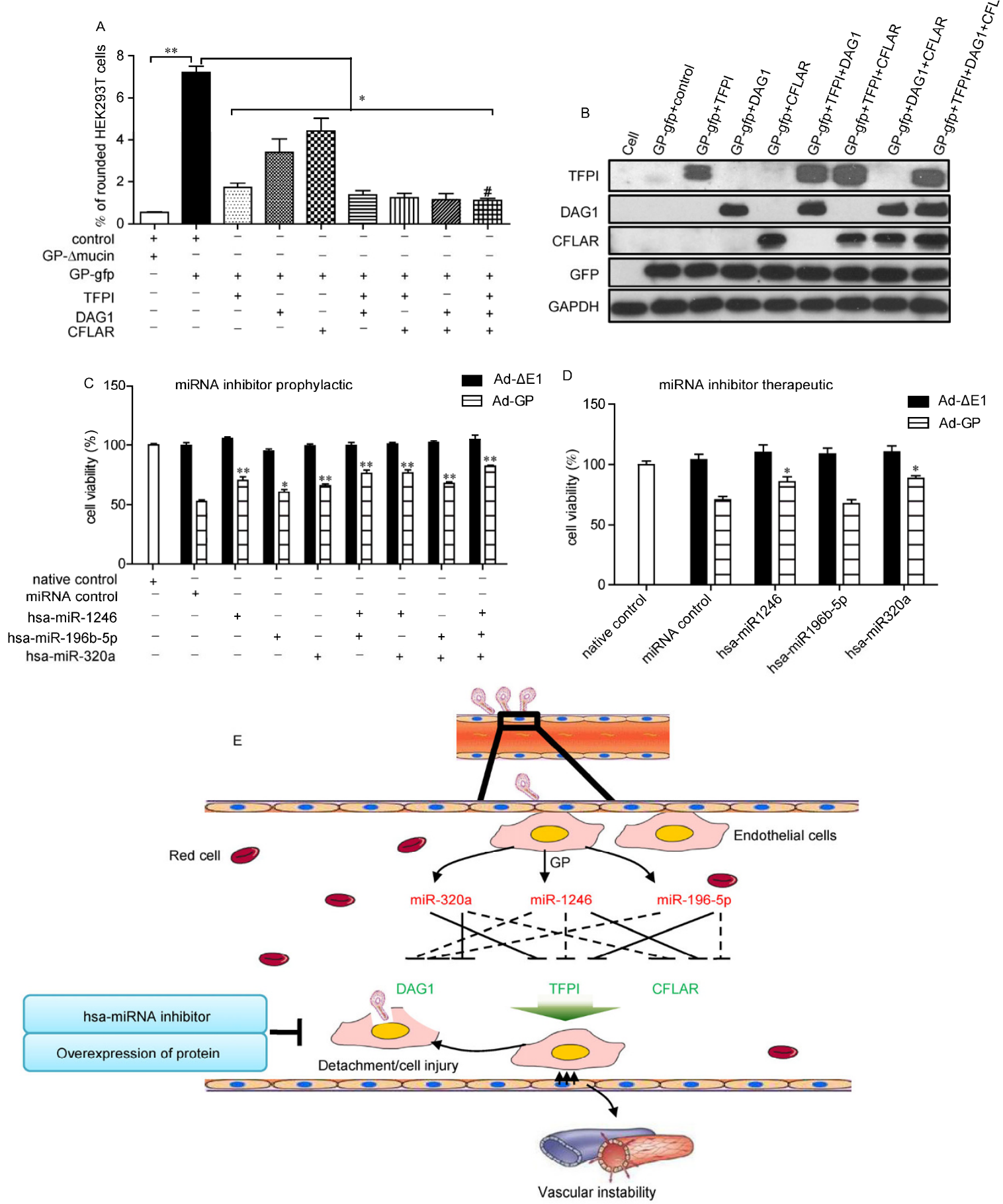

Figure 6 miRNA inhibitors and recombinant proteins could be potential prophylactic and therapeutic remedies against EBOV infections. A, HEK293T cells were cotransfected with $0.5 \mu \mathrm{g}$ of Peak13-gp-gfp or Peak13-gp- $\Delta$ mucin and $0.5 \mu \mathrm{g}$ of control plasmid/Peak13-TFPI-flag/Peak13-DAG1-flag/ Peak13-CFLAR-flag in various combinations. The cells were incubated for $48 \mathrm{~h}$, and both floating and adherent cells were counted to calculate the percentage rounding. The data are from three experiments. *, $P<0.05$; **, $P<0.01$. \#, $P<0.05$, the percentage rounding between overexpression of TFPI and combined overexpression of all three proteins. B. HEK293T cells were cotransfected with $0.5 \mu \mathrm{g}$ of Peak13-GP-gfp and $0.5 \mu \mathrm{g}$ of control plasmid/Peak13-TFPI-flag/Peak13-DAG1-flag/Peak13-CFLAR-flag in various combinations. Protein expression levels were assayed by Western blot at $48 \mathrm{~h}$ after transfection. C, miRNA inhibitors (final concentration of each miRNA, $50 \mathrm{nmol} \mathrm{L}^{-1}$ ) were transfected into HUVECs $24 \mathrm{~h}$ before the cells were exposed to Ad-GP and Ad- $\triangle \mathrm{E} 1$ (MOI, 500) in various combinations. Cell viability was assayed by MTS at $48 \mathrm{~h}$ after transduction. The data are shown as the mean \pm SEM of three experiments. *, $P<0.05$; **, $P<0.01$. D, The cells were exposed to Ad-GP and Ad- $\Delta$ E1 (MOI, 500 ) $3 \mathrm{~h}$ before HUVECs were transfected with control inhibitors or miRNA inhibitors as indicated at a final concentration of $100 \mathrm{nmol} \mathrm{L}^{-1}$. After $48 \mathrm{~h}$, the cell viability was assayed. The data are shown as the mean \pm SEM of three independent experiments. *, $P<0.05$. E, A summary schematic shows the potential pathogenesis of Ebola glycoprotein-induced cell rounding and detachment in human umbilical vein endothelial cells. Up-regulated genes are shown in red; down-regulated genes are shown in green. 
studies are necessary. TFPI has been reported to inhibit tissue factor-mediated coagulation in addition to its role in cell adhesion [49]. Previous studies have shown that treatment with recombinant nematode anticoagulant protein c2 (rNAPc2) significantly increased the survival rate of EBOV-infected non-human primates [50]. We showed here that TFPI was the most effective protein at rescuing EBOV GP-induced detachment and death, indicating that TFPI may have combined roles in cell adhesion and coagulation.

As GP alone could induce cell detachment and increase the permeability of blood vessels [20], in this study we used GP EBOV expression instead of live EBOV and HUVECs instead of whole organism. In addition, the molecular mechanism elucidated here focused on the disruption of adhesion molecules involved in late-stage disease pathogenesis. Although these results may reflect the molecular events that take place during pathogenesis of live EBOV infection, further studies with live EBOV are needed.

At present, no effective filovirus vaccine has been developed. As the only surface envelope glycoproteins of ebola virus, GP is a kind of multifunctional proteins in virus adsorption, cells cytotoxicity and host immune response. At the same time, it is the most ideal vaccine antigen [51]. Considering the safety and immunogenicity of vaccine, the dosage levels of the vaccine must be restricted strictly. GP can induce cell cytotoxicity when it was highly expressed but not moderately expressed [47]. Ongoing and upcoming EBOV GP studies will provide scientific basis for development of candidate preventive vaccine.

In summary, this study provided novel insight into the molecular pathogenesis of Ebola virus infection. In particular, we show that EBOV GP induces elevated expression of hsa-miR-1246, hsa-miR-320a and hsa-miR-196b-5p; decreases expression of their cell adhesion-related target genes TFPI, DAGI and CFLAR; disrupts the integrity of blood vessels to increase vascular permeability and the leakage of red blood cells; and finally contributes to the highly lethal hemorrhagic fever syndrome observed in humans (Figure $6 \mathrm{E})$. Thus, we suggest that inhibitors of hsa-miR-1246, hsa-miR-320a, and hsa-miR-196b-5p, as well as recombinant TFPI, DAG1 and CFLAR target proteins may represent prophylactic and therapeutic remedies against future EBOV infection.

The authors declare that they have no conflict of interest.

This work was supported by the National Natural Science Foundation of China (81230002, 81300057, 91019016, 31361163004), National Basic Research Program of China (2012CB316503), Ministry of Health (201302017), Ministry of Science and Technology of China (2006AA02Z152) and Program of Introducing Talents of Discipline to Universities (B08007). LI DangSheng acknowledged the support of the Science and Technology Commission of Shanghai Municipality (07pj14096).
1 Colebunders R, Borchert M. Ebola haemorrhagic fever-a review. J Infect, 2000, 40: 16-20

2 Kuhn JH, Becker S, Ebihara H, Geisbert TW, Johnson KM, Kawaoka Y, Lipkin WI, Negredo AI, Netesov SV, Nichol ST, Palacios G, Peters CJ, Tenorio A, Volchkov VE, Jahrling PB. Proposal for a revised taxonomy of the family filoviridae: classification, names of taxa and viruses, and virus abbreviations. Arch Virol, 2010, 155: 2083-2103

3 Nkoghe D, Formenty P, Leroy EM, Nnegue S, Edou SY, Ba JI, Allarangar Y, Cabore J, Bachy C, Andraghetti R, de Benoist AC, Galanis E, Rose A, Bausch D, Reynolds M, Rollin P, Choueibou C, Shongo R, Gergonne B, Kone LM, Yada A, Roth C, Mve MT. Multiple Ebola virus haemorrhagic fever outbreaks in gabon, from October 2001 to April 2002. Bull Soc Pathol Exot, 2005, 98: 224-229

4 Simmons G, Wool-Lewis RJ, Baribaud F, Netter RC, Bates P. Ebola virus glycoproteins induce global surface protein down-modulation and loss of cell adherence. J Virol, 2002, 76: 2518-2528

5 Peters CJ, LeDuc JW. An introduction to Ebola: the virus and the disease. J Infect Dis, 1999, 179(Suppl 1): ix-xvi

6 Takada A, Watanabe S, Ito H, Okazaki K, Kida H, Kawaoka Y. Downregulation of beta1 integrins by Ebola virus glycoprotein: implication for virus entry. Virology, 2000, 278: 20-26

7 Chan SY, Empig CJ, Welte FJ, Speck RF, Schmaljohn A, Kreisberg JF, Goldsmith MA. Folate receptor-alpha is a cofactor for cellular entry by marburg and Ebola viruses. Cell, 2001, 106: 117-126

8 Alvarez CP, Lasala F, Carrillo J, Muniz O, Corbi AL, Delgado R. C-type lectins DC-SIGN and L-SIGN mediate cellular entry by Ebola virus in cis and in trans. J Virol, 2002, 76: 6841-6844

9 Takada A, Fujioka K, Tsuiji M, Morikawa A, Higashi N, Ebihara H, Kobasa D, Feldmann H, Irimura T, Kawaoka Y. Human macrophage C-type lectin specific for galactose and $\mathrm{N}$-acetylgalactosamine promotes filovirus entry. J Virol, 2004, 78: 2943-2947

10 Shimojima M, Takada A, Ebihara H, Neumann G, Fujioka K, Irimura T, Jones S, Feldmann H, Kawaoka Y. Tyro3 family-mediated cell entry of Ebola and Marburg viruses. J Virol, 2006, 80: 10109-10116

11 Carette JE, Raaben M, Wong AC, Herbert AS, Obernosterer G, Mulherkar N, Kuehne AI, Kranzusch PJ, Griffin AM, Ruthel G, Dal Cin P, Dye JM, Whelan SP, Chandran K, Brummelkamp TR. Ebola virus entry requires the cholesterol transporter Niemann-Pick $\mathrm{C} 1$. Nature, 2011, 477: 340-343

12 Kondratowicz AS, Lennemann NJ, Sinn PL, Davey RA, Hunt CL, Moller-Tank S, Meyerholz DK, Rennert P, Mullins RF, Brindley M, Sandersfeld LM, Quinn K, Weller M, McCray PB Jr., Chiorini J, Maury W. T-cell immunoglobulin and mucin domain 1 (TIM-1) is a receptor for Zaire Ebolavirus and Lake Victoria Marburgvirus. Proc Natl Acad Sci USA, 2011, 108: 8426-8431

13 Miller EH, Obernosterer G, Raaben M, Herbert AS, Deffieu MS, Krishnan A, Ndungo E, Sandesara RG, Carette JE, Kuehne AI, Ruthel G, Pfeffer SR, Dye JM, Whelan SP, Brummelkamp TR, Chandran K. Ebola virus entry requires the host-programmed recognition of an intracellular receptor. EMBO J, 2012, 31: 1947-1960

14 White JM, Schornberg KL. A new player in the puzzle of filovirus entry. Nat Rev Microbiol, 2012, 10: 317-322

15 Chan SY, Speck RF, Ma MC, Goldsmith MA. Distinct mechanisms of entry by envelope glycoproteins of Marburg and Ebola (Zaire) viruses. J Virol, 2000, 74: 4933-4937

16 Ito H, Watanabe S, Sanchez A, Whitt MA, Kawaoka Y. Mutational analysis of the putative fusion domain of Ebola virus glycoprotein. J Virol, 1999, 73: 8907-8912

17 Lee JE, Fusco ML, Hessell AJ, Oswald WB, Burton DR, Saphire EO. Structure of the Ebola virus glycoprotein bound to an antibody from a human survivor. Nature, 2008, 454: 177-182

18 Feldmann H, Geisbert TW. Ebola haemorrhagic fever. Lancet, 2011, 377: 849-862

19 Ray RB, Basu A, Steele R, Beyene A, McHowat J, Meyer K, Ghosh AK, Ray R. Ebola virus glycoprotein-mediated anoikis of primary human cardiac microvascular endothelial cells. Virology, 2004, 321: 
$181-188$

20 Yang ZY, Duckers HJ, Sullivan NJ, Sanchez A, Nabel EG, Nabel GJ. Identification of the Ebola virus glycoprotein as the main viral determinant of vascular cell cytotoxicity and injury. Nat Med, 2000, 6: 886-889

21 Sullivan N, Yang ZY, Nabel GJ. Ebola virus pathogenesis: implications for vaccines and therapies. J Virol, 2003, 77: 9733-9737

22 Sullivan NJ, Peterson M, Yang ZY, Kong WP, Duckers H, Nabel E, Nabel GJ. Ebola virus glycoprotein toxicity is mediated by a dynamin-dependent protein-trafficking pathway. J Virol, 2005, 79: 547-553

23 Zampieri CA, Fortin JF, Nolan GP, Nabel GJ. The ERK mitogen-activated protein kinase pathway contributes to Ebola virus glycoprotein-induced cytotoxicity. J Virol, 2006, 81: 1230-1240

24 Wahl-Jensen VM, Afanasieva TA, Seebach J, Stroher U, Feldmann H, Schnittler HJ. Effects of Ebola virus glycoproteins on endothelial cell activation and barrier function. J Virol, 2005, 79: 10442-10450

25 Geisbert TW, Young HA, Jahrling PB, Davis KJ, Kagan E, Hensley LE. Mechanisms underlying coagulation abnormalities in Ebola hemorrhagic fever: overexpression of tissue factor in primate monocytes/macrophages is a key event. J Infect Dis, 2003, 188: 1618-1629

26 Ruf W. Emerging roles of tissue factor in viral hemorrhagic fever. Trends Immunol, 2004, 25: 461-464

27 Bray M, Geisbert TW. Ebola virus: the role of macrophages and dendritic cells in the pathogenesis of Ebola hemorrhagic fever. Int J Biochem Cell Biol, 2005, 37: 1560-1566

28 Sobarzo A, Ochayon DE, Lutwama JJ, Balinandi S, Guttman O, Marks RS, Kuehne AI, Dye JM, Yavelsky V, Lewis EC, Lobel L. Persistent immune responses after Ebola virus infection. N Engl J Med, 2013, 369: 492-493

29 Boehm M, Slack FJ. microRNA control of lifespan and metabolism. Cell Cycle, 2006, 5: 837-840

30 Carleton M, Cleary MA, Linsley PS. microRNAs and cell cycle regulation. Cell Cycle, 2007, 6: 2127-2132

31 Scaria V, Hariharan M, Maiti S, Pillai B, Brahmachari SK. Host-virus interaction: a new role for microRNAs. Retrovirology, 2006, 3 : 68

32 Lecellier $\mathrm{CH}$, Dunoyer $\mathrm{P}$, Arar K, Lehmann-Che J, Eyquem S, Himber C, Saib A, Voinnet O. A cellular microRNA mediates antiviral defense in human cells. Science, 2005, 308: 557-560

33 Motsch N, Pfuhl T, Mrazek J, Barth S, Grasser FA. Epstein-Barr virus-encoded latent membrane protein 1 (LMP1) induces the expression of the cellular microRNA miR-146a. RNA Biol, 2007, 4: 131-137

34 Song L, Liu H, Gao S, Jiang W, Huang W. Cellular microRNAs inhibit replication of the H1N1 influenza A virus in infected cells. J Virol, 2010, 84: 8849-8860

35 Trapnell C, Roberts A, Goff L, Pertea G, Kim D, Kelley DR, Pimentel H, Salzberg SL, Rinn JL, Pachter L. Differential gene and transcript expression analysis of RNA-seq experiments with Tophat and Cufflinks. Nat Prot, 2012, 7: 562-578

36 An J, Lai J, Lehman ML, Nelson CC. 2-miRDeep*: an integrated application tool for miRNA identification from RNA sequencing data. Nucleic Acids Res, 2013, 41: 727-737

37 Richardson JS, Yao MK, Tran KN, Croyle MA, Strong JE, Feldmann H, Kobinger GP. Enhanced protection against Ebola virus mediated by an improved adenovirus-based vaccine. PLoS One, 2009, 4: e5308
38 Jia YY, Gao P, Chen HZ, Wan YZ, Zhang R, Zhang ZQ, Yang RF, Wang $\mathrm{X}, \mathrm{Xu}$ J, Liu DP. SIRT1 suppresses PMA and ionomycin-induced ICAM-1 expression in endothelial cells. Sci China Life Sci, 2013, 56: 19-25

39 Chan SY, Ma MC, Goldsmith MA. Differential induction of cellular detachment by envelope glycoproteins of Marburg and Ebola (Zaire) viruses. J Gen Virol, 2000, 81: 2155-2159

40 Provencal M, Michaud M, Beaulieu E, Ratel D, Rivard GE, Gingras D, Beliveau R. Tissue factor pathway inhibitor (TFPI) interferes with endothelial cell migration by inhibition of both the Erk pathway and focal adhesion proteins. Thromb Haemost, 2008, 99: 576-585

41 Chen J, Zhang B, Pan C, Ren L, Chen Y. Effects of monocyte chemotactic protein-3 on ICAM-1, VCAM-1, TF, and TFPI expression and apoptosis in human umbilical vein endothelial cells (in Chinese). Nan Fang Yi Ke Da Xue Xue Bao, 2013, 33: 86-92

42 Belkin AM, Smalheiser NR. Localization of cranin (dystroglycan) at sites of cell-matrix and cell-cell contact: recruitment to focal adhesions is dependent upon extracellular ligands. Cell Adhesion Commun, 1996, 4: 281-296

43 Park D, Shim E, Kim Y, Kim YM, Lee H, Choe J, Kang D, Lee YS, Jeoung D. C-FLIP promotes the motility of cancer cells by activating FAK and ERK, and increasing MMP-9 expression. Mol Cells, 2008, 25: $184-195$

44 Winckers $\mathrm{K}$, ten Cate H, Hackeng TM. The role of tissue factor pathway inhibitor in atherosclerosis and arterial thrombosis. Blood Rev, 2013, 27: 119-132

45 He MX, He YW. CFLAR/c-FLIPL: a star in the autophagy, apoptosis and necroptosis alliance. Autophagy, 2013, 9: 791-793

46 Karolchik D, Barber GP, Casper J, Clawson H, Cline MS, Diekhans M, Dreszer TR, Fujita PA, Guruvadoo L, Haeussler M, Harte RA, Heitner S, Hinrichs AS, Learned K, Lee BT, Li CH, Raney BJ, Rhead B, Rosenbloom KR, Sloan CA, Speir ML, Zweig AS, Haussler D, Kuhn RM, Kent WJ. The UCSC Genome Browser database: 2014 update. Nucleic Acids Res, 2014, 42: D764-770

47 Alazard-Dany N, Volchkova V, Reynard O, Carbonnelle C, Dolnik O, Ottmann M, Khromykh A, Volchkov VE. Ebola virus glycoprotein GP is not cytotoxic when expressed constitutively at a moderate level. J Gen Virol, 2006, 87: 1247-1257

48 Herquel B, Ouararhni K, Khetchoumian K, Ignat M, Teletin M, Mark M, Bechade G, van Dorsselaer A, Sanglier-Cianferani S, Hamiche A, Cammas F, Davidson I, Losson R. Transcription cofactors TRIM24, TRIM28, and TRIM33 associate to form regulatory complexes that suppress murine hepatocellular carcinoma. Proc Natl Acad Sci USA, 2011, 108: 8212-8217

49 Adams M. Tissue factor pathway inhibitor: new insights into an old inhibitor. Semin Thromb Hemost, 2012, 38: 129-134

50 Geisbert TW, Hensley LE, Jahrling PB, Larsen T, Geisbert JB, Paragas J, Young HA, Fredeking TM, Rote WE, Vlasuk GP. Treatment of Ebola virus infection with a recombinant inhibitor of factor VIIa/tissue factor: a study in rhesus monkeys. Lancet, 2003, 362: 1953-1958

51 Ledgerwood JE, Costner P, Desai N, Holman L, Enama ME, Yamshchikov G, Mulangu S, Hu Z, Andrews CA, Sheets RA, Koup RA, Roederer M, Bailer R, Mascola JR, Pau MG, Sullivan NJ, Goudsmit J, Nabel GJ, Graham BS. A replication defective recombinant Ad5 vaccine expressing Ebola virus GP is safe and immunogenic in healthy adults. Vaccine, 2010, 29: 304-313

Open Access This article is distributed under the terms of the Creative Commons Attribution License which permits any use, distribution, and reproduction in any medium, provided the original author(s) and source are credited. 


\section{Supporting Information}

Figure S1 Differentially expressed miRNAs (DEmiRs) and differentially expressed genes (DEGs) in the process of glycoprotein-induced vascular endothelial cell injury.

Figure S2 Ebola virus GP expression induced cell rounding and death.

Figure S3 Analysis of target genes of miRNAs by Western blot.

Figure S4 Analysis of miRNA target genes by luciferase.

Figure S5 KIAA1429, ZCCHC6 and CPD could not ameliorate Ebola virus GP-induced cytotoxicity.

Figure S6 Genomic locations of microRNAs hsa-miR-1246, hsa-miR-196b-5p and hsa-miR-320a.

Table S1 Primer sequences

Table S2 Primary antibodies

Table S3 Expression fold change of 18 miRNAs which were found to be significantly differentially expressed in the GP-induced HUVECs

The supporting information is available online at life.scichina.com and link.springer.com. The supporting materials are published as submitted, without typesetting or editing. The responsibility for scientific accuracy and content remains entirely with the authors. 